\title{
Mimis Souliotis: A Poet with Balkan Historical Coordinates
}

\author{
Triantafyllos H. Kotopoulos, Angeliki Pechlivani \\ University of Western Macedonia, Florina, Greece
}

\begin{abstract}
Mimis Souliotis, who was a poet, belongs to the lyrical generation of the 70's, a typically "urban", literary period in the sense that poetry is part of a neo-realist framework along the lines of its great ancestors, Cavafy and Karyotakis. M. Souliotis deviates from the "urban poetry" of his prominent fellow-craftsmen. Despite of his having been brought up and nurtured in big cities (Athens, Thessaloniki), his poetry has northwestern coordinates and focuses on Florina, his long-term domicile. As part of the northwest region of the Balkanian Macedonia, Florina is the main spacial work stream of his poetry, a reference field that is not only geographical but also deeply historical and existential. The provincial heartland of the Balkanian Macedonia enlarges upon his work repeatedly-either as a geophysical landscape and as a river network, or as a climatic reality, as a historical reference and cultural tradition at times and, more often than not, as a linguistic impact, provided that there are several Slavic place names in his poetry. The Balkanian province is neither M. Soulioti's nostalgic reminiscence nor a painful flashback and, simultaneously, a redeeming feature in the past. It is nothing but his vividly experienced era, across his whole space-time fluidity. The ubiquitous use of rural area in M. Soulioti's poetry is not either a sightseeing "aspect" or a self- governed geographic entity but pure History and Language. He is interwoven with historical experiences and linguistic idioms from The Dust of Time an ontology and existence, not bound to national geographical lines. It is a perpetual and indissoluble Balkan anthropology experienced as part of an everyday reality.
\end{abstract}

Keywords: Souliotis, Balkan poetry

\section{Indicative Quotes Concerning the Poetic Generation of the 70s}

The poet Mimis Souliotis belongs to the poetic generation of the 70s, known as the generation of "defiance" (Varikas, 1970), since "defiance" constituted its main ideological and political mark. More specifically, in the early years of its occurrence that coincided with the Colonels' dictatorship (1967-1974), its representatives in their entirety defy everything. Internationalists, deniers of the establishment and in total anger with the Colonels, they reacted against the alienating reality of their time and, to a great extend, against the way of writing and to the poetic ethos of the representatives of the poetic "generations" that preceded it.

The generation's major stylistic feature, directly connected with its "defiance" stance, is that of humour and irony, which often verges on the satire and the burlesque expression. In this way, its representatives articulate a subversive and iconoclastic discourse, directed against "any orthodoxy" (Ziras, 1979).

Triantafyllos H. Kotopoulos, Associate Professor of Creative Writing and Modern Literature, University of Western Macedonia.

Angeliki Pechlivani, Philologist, PGCE Literature Graduate of “Creative Writing”, University of Western Macedonia. 
Their language is invariably ordinary, with elements of the oral discourse, their vocabulary is often "trivial" and their imagery is bluntly realistic. The linguistic acidity that prevails during the first "defying" decade later evolves into milder expressive tropes, more personal and confessional. The provocative, chaotically denunciatory and occasionally bawdy language of the early 70 s, becomes during the following decades more insinuative and peculiarly lyrical.

The topics of the 70s generation are diverse and often focus on issues of minor importance, utilizing the triteness, the off-centre and the 'irrelevant'. But all these "minor" elements revolve like satellites around Poetry's key themes, which are anyway few—love, death, time, freedom, loneliness and, of course, poetry itself. It is typical that in the 170 s generation, the "poetics"'s poems - that is, those poems that their main subject is the very process of writing poetry-increase dramatically.

As far as the form is concerned, the poets of this generation adopt the free verse, often engaging in its prosaic elaboration, while they generally prefer short versed poems, in a 'minor scale'. The preference of the 70 s generation's representatives for small, sometimes instantaneous, poems is probably the offspring of a basic thematic selection of most of its members, the wandering and precipitation in the private sphere-which, by definition, is of more limited dimensions than the public one.

The 70s Generation's constitute a wide intertextual grid. The poets' pluralism, as well as their ability (or their need) to deliberately integrate earlier voices, is a sort of a trademark. According to A. Ziras, this particular generation "has the most intense and overwhelming tendency to absorb [into its poetical corpus] other works" (Ziras, 2001).

M. Souliotis bears his generation's stamp, maybe not as evidently as his other companions. There are several specific features that distinguish him, and their combination forms the peculiarity of his poetry. In conclusion, M. Souliotis is organically included in the 70 s generation, sometimes converging in its "tough" morphological, aesthetic and ideological core and sometimes diverging but always remaining centrifugally in its orbit.

\section{Urban Landscape and Provincial Hinterland in the 70s Generation Poetry}

In the 70s Generation poetry the urban landscape is dominating; therefore, and perhaps according to the pattern set by Cavafy and Karyotakis, the poetry of this generation falls within a neo-realistic urban framework. The "dead-end" city (Savvides, 1973-1978) is stuffy and oppressive. Consumerism, technology, town planning and the labyrinthine urban web constitute a threat for the poetic subject. The city intensifies loneliness and infuses it with grief. However, admiration, or rather ambivalence, is also present (Psachou, 2011). Athens is pretty and tough, "epic and lost" (C. Markopoulos), alive and absurd. The city, as a major thematic axis, also delimits the poetry of this generation, a poetry of the "interiors", a poetry that possesses an asthmatic rhythm and a "close" horizon, a poetry that its standpoint is essentially minimalist. Of course, there are poetical voices that retrogressively resonate to their birthplace, creating provincial inland pockets, sometimes bearing the mark of relieving nostalgia and some other times of harsh historical memory. Michalis Ganas and Christos Bravos are two of the most characteristic poets that exhibit this particular tendency.

M. Souliotis deviates from his peers' "urban poetry" in a distinctive way. Although he was brought up and came into age in Greece's biggest cities (Athens, Thessaloniki) and, as he himself asserted, a "man of many 
places" (Souliotis, 2001), his poetry's coordinates - metaphorically speaking — have north-western orientation and focus on the city of Florina, where he spent most (and the last) of the years of his life. He is most definitely connected to the north-western part of the erstwhile Balkan Macedonia with blood ties (his mother was born in Florina and his maternal grandmother came from Monastiri). Florina, thus, and the north-western region of Macedonia in general, constitute the main spatial axis of his poetry, a point of reference that is not only geographical and morphological, but also deeply historical and existential.

\section{Regarding the History of North-western Balkan Macedonia}

Balkans, a region that is extended from the Mediterranean Sea to Central Europe and the Black Sea and borders with the oilfields of Middle East, has always been at the crossroads between East and West. On the one hand, their historical fortunes have been shaped by their significant geostrategic position and by the great mountainous masses that form their mainland, crossing it vertically and horizontally; on the other hand, by the ethnic, religious and social diversity in a relatively limited space, which led to a violent history and to the liquidity of their internal borders.

In the late 19th century and in the early 20th century, the Balkan Peninsula is characterized by a proliferation of nations, languages and religions. More specifically, in the West Balkan zone that we are referring to, Orthodox Greeks, Patriarchal Albanians, Exarchat Bulgarians, Muslim Turks, Jews, etc. have co-existed. After the end of the Balkan wars andthe First World War, and on the basis of the Treaties of Bucharest and Neuilly, the wider region of Macedonia was divided (Greece took $52 \%$, Serbia $38 \%$ and Bulgaria $10 \%$ of its land mass). The Macedonian issue, which had emerged within the late Ottoman Empire and its decomposition process, seemed to have been resolved, especially with the exchange of the populations - appearingly so. But the presence of about 80,000 Slavophone Macedonians in West Macedonia - many of whom with Slavic ethnic conscience-, the position adopted by the Balkan Communist parties— the Greek Communist Party included — for an independent Macedonian nation or an autonomous Macedonia, the fragile balance and the subterranean conflicts in the newly founded state of Yugoslavia along with Bulgaria's revisionist policies as far as the state borders is concerned preserved the matter in a dormancy state.

During the Occupation by the Axis powers (1941-1944), the active Bulgarian propaganda and some of the policies adopted by the Bulgarian occupation authorities was welcomed in the prefectures of Pella, Kastoria and Florina, where there have been Slav-Macedonian pockets- this situation resulted to the cooperation of a significant portion of Slavic Macedonians with the German and Bulgarian Occupation authorities in Western Macedonia. During the Greek Civil War, some Slavic-Macedonians, influenced by Tito's pronouncements on a prospective Macedonian state, established the SNOF, a resistance organization that, by convention, allied with ELAS. The Greek Democratic Army's final defeat was followed by the expulsion of 35,000 Slavophones to Yugoslavia, while many more remained in Western Greek Macedonia (where they have been found themselves under constant oppression).

In the following decades, there have been continuous forced migrations, displacements and refugee movements in the region of Western Macedonia, but also new states' formations, through the imaginary construction of a "national" conscience and a social memory (which was mainly orally transmitted) that did not align with the official historiography. 


\section{The Balkan Historical Coordinates in M. Souliotis's poetry}

The provincial hinterland of northwestern Balkan Macedonia leaves repeatedly its mark on the poetry of M. Souliotis; this can be established by the numerous Greek and Slavic place names in his poems (Prespes, Ostrov, Perasma, Negovani, Vitolia, Patel, Meliti, Korestia, Kladorrachi, Ano Kalliniki, Ydrousa etc.). The geomorphology and the geophysical formation of the area, for example, as in the following extracts,

In the northwest of Philip's territory, where

I live

more permanently than temporarily, in the gorge-city which repines

due to the ice brume and the snow,

kilometers away from all the seas, but close to

Monastiri... (Deep Surface) (Souliotis, 1992, p. 9)

and

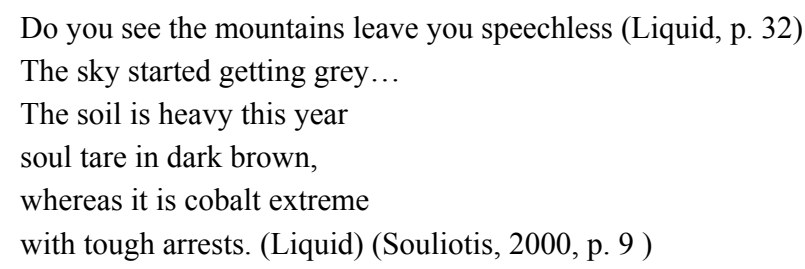

As well as the adverse climatic conditions, for example,

Today it's raining oblique phalanx

and the ice brume is steaming like a direction

on the slopes of South-Western Balkan

the wind is hemming the rain and twisting the mist

and there he is the phantom of the Peninsula

the blearest in Prespes sibling sisters. (Scottish Sun) (Souliotis, 2001, p. 37)

Or,

Cold and unperturbed ether, without dust

frost burns the landscape,

the uncuthaze floats over Korestia,

in the frosty stacks of firewood. (Old Ages) (Souliotis, 2002, p. 12)

And again,

Then a wind began to blow

from Banitsa to the area endings

it crushed trees, in Kleidi it pushed dogs

cars were burried and noses fell.

In Amynteo it took shutters

houses had turned on self-defense lights... (Old Ages) (Souliotis, 2002, p. 36)

Delineate an inescapable space, a "terminal place" (Old Ages, p.11), in which the poetic subject is being trapped

... [carrying] the old winters like a hard shell, which turns white 
on the edge of the bent Ohrid tiles... (Liquid)

and where the sea turns to be an existential need

... and with a throat deprived of iodine and risk

for goiter,

"Sea! Sea" I sighed sincerely....

eight hundred meters above the surface of the Aegean...(Deep Surface). (Souliotis, 1992, p. 9)

Of course, despite the suffocation caused by this enclosed mountainous place, the poet expresses his firm conviction regarding the psychotherapeutic properties it possesses, thus pronouncing this conviction in the form of an axiomatic truth:

...Whoever flees from anywhere

always travels northwest...

not to melt his soul

south and east. (Old Ages) (Souliotis, 2002, p. 25)

Occasionally, he asserts his parochial pride,

South-West where I live ...

fog doesn't let the sun to discomfort us,

the rain and the snow nourish dark green vegetables

and instead of arid palms, sentimental linden

flourish... (Cyprus indeed); (Souliotis, 2011, p. 45)

Some other times he adopts lyrical tones assuming an almost supernatural sense

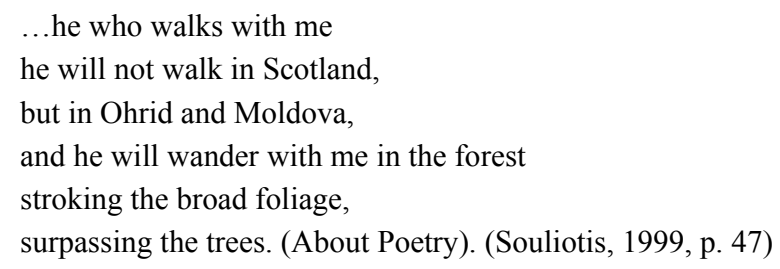

For Mimis Souliotis, the Balkan province does not constitute a nostalgic recollection and a return to a beautified childhood·(besides, Florina and generally western Macedonia do not constitute M. Souliotis's birthplace, the space where he spent his childhood and where his first memories were structured).

We are not dealing here with a painful and simultaneously redeeming flashback to the past; this is his actual. The Macedonian rural area does not institute a tourist's "gaze" in his poetry; rather, it is the very living present experienced through all his senses. People, occupations, products, social relations and events are themed in his poetry, giving it a particular local, Macedonian character. The zantrougka (a type of a primitive collective up to the early 20th century), the Balkan brass, the dances (e.g, the poustseno dance), the tsipouro distilleries and the traditional festivals that accompany its production; the dry wine of Amyntaio, trout, the roach and carp of Prespes Lakes and Vegoritida, beans, the chili peppers - all these and many other construct a Balkan social anthropology that is experienced as an everyday reality.

A very interesting point in M. Souliotis's poetry is that the border areas of north-western Macedonia is interpolated in his oeuvre as a linguistic fingerprint as well. His poetry is

Words multilingual (“Old Ages", Souliotis, 2002, p.11) 
and

... grammatical, productional strings and lexical hordes...

over the embankments of successive centuries,

in the spoken liquid of southern Macedonia which takes to Slavic. (Deep Surface, Souliotis, 1992, p. 34).

Still,

In the South-West where I permanently reside temporarily...

Speech is uttered like belated, with withholding

sounds ... (Cyprus indeed) (Souliotis, 2011, p.45)

And again

$\ldots$ in the consonantal surnames [the Macedonian]

that their vowels are not here: Vertkas,

no restoration, but sounding,

time took them: squeezed and pressed

Vertkas, Momtsis ...

by chased mouths

and anxious hearing, intermarriage silts

these emerged (Deep Surface). (Souliotis, 1992, p. 21)

Mostly, however, the language of this region is reflected in his poetry as a continuous process of interactions through time, that without raising its national stigma, simultaneously does not deny the perpetual osmosis. A typical poem is:

\section{Mou rekoftena popo}

Take for example the sudden death

in the agricultural community of Ano Kalliniki...

when the old aged woman comes out of the kitchen...

and asks the teacher "mou rekofte na popo"...

He felt that slavophany exposes him

and replied "Yes! The priest was alerted" louder

to recoup. But if we had informed him

that "rekofte" is a modulation of "erexate"

of Iliad and identical with caucasian "erouxen"

and that they reflect the differentiation of ages,

then he could be self-controlled

and wait for the priest undaunted, not ignorant of history. (Deep Surface). (Souliotis, 1992, p. 32)

The poetry of M. Souliotis abounds with words of Slavic origin and place names (onteforme, Ljube, piktsiorines... Sfetapetka, Pesosnitsa etc.), thereby expressing, and confirming, an inescapable historical reality in northwestern Macedonia: that of the presence of Slavic Macedonians and their linguistic, mainly, footprint. The fact that he does not hesitate to include Slavic words in his poems proves that the poet distances himself from an "easy" poetic ethnocentrism and an 'expurgated' Greek character which could be considered as desirable, if not "bounden" and expected options, especially in the last decades because of the well known diplomatic tensions with the neighboring country (FYROM). 
The area of northwestern Macedonia, beyond the geomorphological, climatic, social and linguistic imprint that leaves on poetry of M. Souliotis, is also delineated resoundingly in the form of historical references. Thus, this region is referred to as:

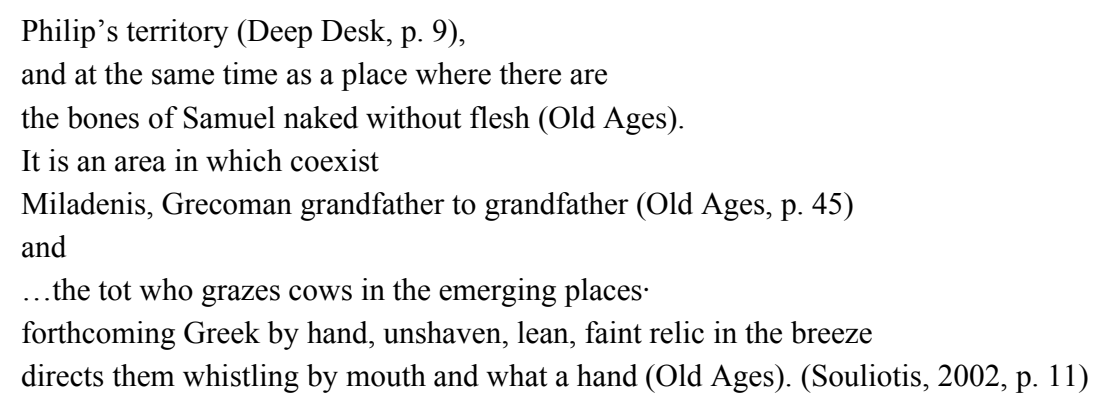

M. Souliotis does not hesitate to directly refer, without metaphoric mediations, to the region's ethnic diversity, and to criticize the "militant" science that distorts the historical truth for the sake of political expediency.

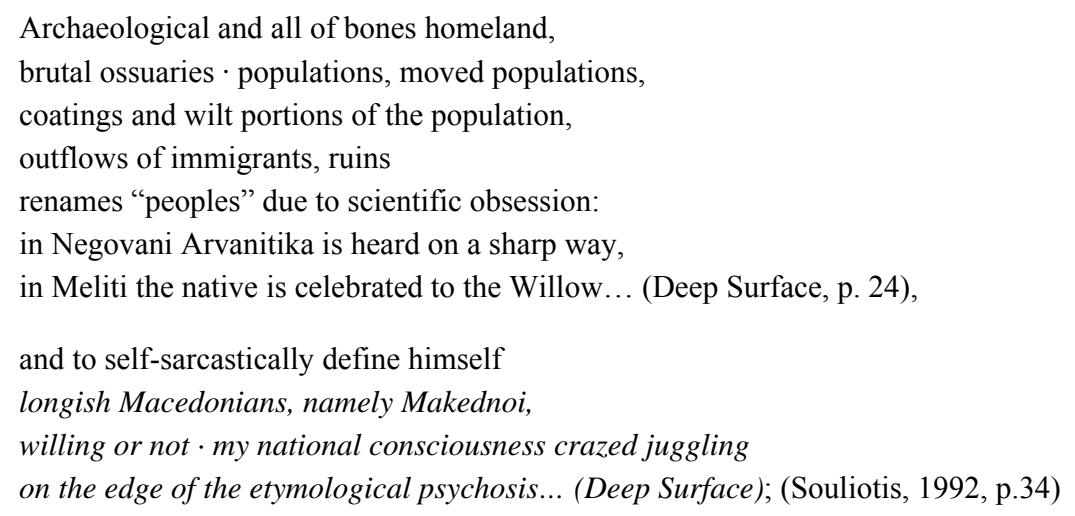

Also, to deconstruct the "typical" Greek landscape, and cheekily subverting the "philhellenic" poetry that reproduces it.

The landscape with the green pines and limes,

that showed the organized tourism

resting others. (Deep Surface). (Souliotis, 1992, p. 24)

The Struggle for Macedonia (1900-1908) is present in his poetry either in the form of Captain Kotas and his stout-hearted men who

...felt that with any outcome

They would be left as exiles in their homeland (Old Ages) (Souliotis, 2002, p. 21)

Or as political interpretation -critical and in an almost essay form- for the policies adopted by particular leaders, as for example in the poem "Cyprus indeed"

So as the 1821 or the Macedonian, and the Cyprian

it is tough to be argued direct

without self-evidence, obsessions and bullshit. 
... to talk about it outright and bluntly we should have had the morality of Karaiskaki or Captain Kotti, which we do not have.

We do not possess it

because the innermost relinquish, the decisions

have preceded,

because we pump up our minds with "bidders" and

"traitors"

instead of understanding in real terms

and engaging in beneficial works. (Souliotis, 2011, p. 32)

The mass migration of Northwestern Balkan Macedonia residents in the early 20th century to America is an event that is themed, with restrained sadness and a sense of futility, in the poetry of M. Souliotis-e.g.,

Before he embarks for New York, 1906:

The ears harmonically balanced, the forehead high-topped

With the sparkle of life in the eyes-

to differentiate from when he dies

with old ears and the formal suit (Scottish Sun) (Souliotis, 2001, p. 39)

And also

The widow aunt Preskourka sent the card

colored by hibernacula of Canada

where she stayed at her son for the first time:

In Florina of Toronto, October 8

Dear brother Nikolakis,

I'm in good health, calluses are also healed,

I desire the same for you, see you again,

I buss you, your cherishing

the name founded by her own hand.

He had caught up to be born in Vitolia,

resided in Florina, wintered in Toronto

and until I write to her, she died. (Liquid) (Souliotis, 2001, p. 56)

The tragic uprooting of the poor migrants from the land of their fathers and ancestors takes on dramatic and metaphysical dimensions in the following touching poem that comes from the collection Sun inScotland:

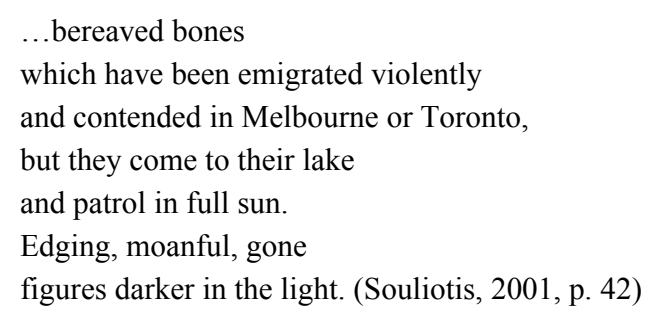

The dominant historical facts, however, in the work of that Akritas (a border-poet par example) are the Occupation and the Civil War, although Mimis Souliotis has not experienced personally that horrible period but mediated through historical sources, oral narratives and the relevant historiography. It is well known that the Occupation in Western Macedonia was three-zoned—shared among Italians (until mid-1943, Bulgarians, and 
Germans - (with several of the Slavophones allied with the Axis forces), while the Civil War (1946-1949) was conducted under extremely harsh and divisive conditions (many Slavic Macedonians who cooperated with the DAG (Democratic Army of Greece), were forced, after its end, to find refuge to the New Yugoslavia). We are reading, therefore, realistic representations of the time.

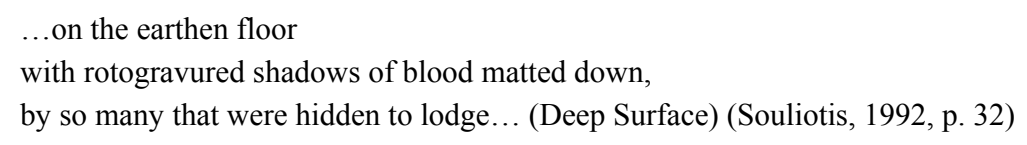

And again,

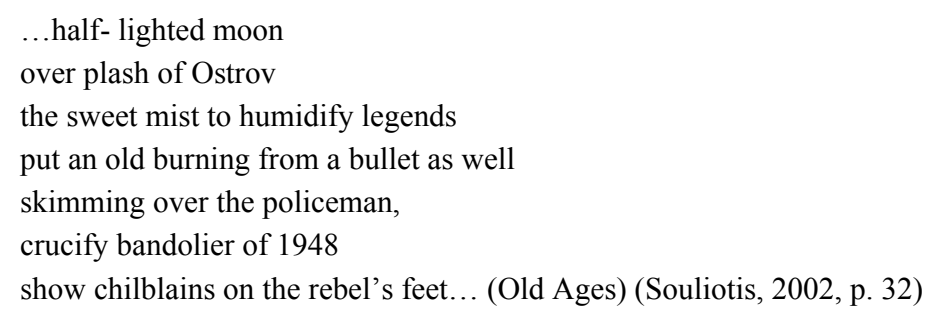

but also lyrical impressions that almost touch the limits of spectral, when the poetic subject does not simply draw memories from the historical past but experiences it as a living reality, identifies itself with the spatio-temporal context

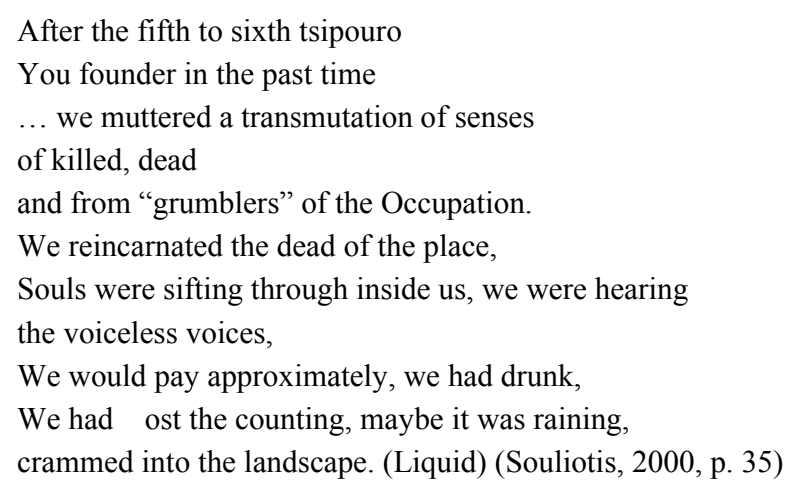

M. Souliotis's relationship with the Northwestern region of Macedonia is one of love. For him, it is a homeland, but not in the sense of his birthplace and the space connected with his childhood memories. It is home in the meaning of blending and polymorphy, heterogeneity and multilingualism, of the multifaceted human harmony. It is a starting point and end

\section{Lemvodia}

...to breathe spring with a common breath and in November the rheumatism together ... we will reside in the same shore of Ohrid where the sun tilts right, in the nice one, and will send the e-mails together, three, five, ten winters heaped and will return by the black boat black cloth, the one-armed with one paddle. (Liquid) (Souliotis, 2000, p. 60) 


\section{Conclusion}

To conclude: Although he belongs to a poetical generation that its main focus is the city landscape and the urban environment, Mimis Souliotis turns his attention above all in the Southewestern Balkan Peninsula and, most specifically, in the Northwestern Macedonia. Both the ethnic and the linguistic variety of this specific area and its turbulent history, as well as its geomorphological and climatological conditions, are captured in his poetry or firmly constitute its background - they are the figured bass of his compositional procedures. One would have claimed, without exaggeration, that it not Mimis Souliotis the one that writes about this much afflicted, tormented region; on the contrary, it is the region, the space, with all its polyphonic connotations, that "writes" the poetry-having Mimis Souliotis only as its medium.

\section{References}

Alexiou, D. (Ed.). (2001). The 70's generation. Athens: Ombros Press.

Anagnostaki, N. (1973). The element of satire and humor in the younger poetic generation. H Synexeia, 4.

Koliopoulos, I. (n.d.). Macedonia in the World War Two vortex. Macedonian Struggle Foundation http://www.imma.edu.gr/imma/history/14.html (retrieved 20/8/2016)

Kostopoulos, T. (2009). The "Macedonian" problem during the 1940's. History of Greece in the 20th century (Reconstruction- Civil War-Restoration), v. D1. (General Editor: Ch. Hatziosif), Athens: Vivliorama Press.

Koulouri, Ch. (2004). Balcan's "new” history. To Vima, February the 2nd.

Maronitis, D. N. (1987). Medium and small ones. Athens: Kedros Press.

Papageorgiou, K. G. (1989). The '70’s generation. History—Poetical paths. Athens: Kedros Press.

Psachou, M. (2011). The 70's poetical generation: An ideological and aesthetic investigation (Doctoral Thesis, Ioannina).

Savvidis, G. P. (1978). Ephemeral sperm 1973-1978. Athens: Hermes Press.

Souliotis, M. (1992). Deep surface. Athens: Kedros Press.

Souliotis, M. (1998). Futile eggs. Athens: Kedros Press.

Souliotis, M. (1999). On poetics (1974-1999). Athens: Hermes Press.

Souliotis, M. (2000). Liquid(s). Athens: Hermes Press.

Souliotis, M. (2001). Florina: A city in literature. Athens: Metaichmio Press.

Souliotis, M. (2001). Scotish sun. Athens: Hermes Press.

Souliotis, M. (2002). Old ages. Athens: Hermes Press.

Souliotis, M. (2011). Kypron in dind. Touring pickups in Verses. Athens: Metaichmio Press.

Souliotis, M. (2014). Coming from Athens. Athens: Hermes Press.

Vagenas, N. (2001). Poetry's expressive impasse. To Vima, January the 26th.

Varikas, V. (1970). The new generation facing the present. To Vima, November the 29th.

Ziras, A. (1989). Elements of genealogy (On the poetry and the poets of the '70s). Athens: Roptron Press.

Ziras, A. (Ed.). (1979). Contemporary Greek poetry, 1965-1980. Athens: Graphi Press.

Ziras, A. (2001). Vassos Varikas and his syncretism: Poetry, prose and rhythmic prose: Study of the interpretation of the genres. Comparison, 12. Hellenic Society of General and Comparative Grammatology. pp. 152-159. 